Ittishal Educational Research Journal January 2021, Vol. 2, No. 01, p. 11 - 21 http://journal.ittishal.net/index.php/ierj

DOI 10.51425/ierj.v2i1.17

\title{
Social Media Based EFL Learning: Opportunities and Challenges
}

\author{
Hisyam Nur Ahmad Latif \\ Universitas Negeri Yogyakarta, Indonesia \\ hisyamnur.2019@student.uny.ac.id
}

\begin{abstract}
The growth of communication medium from traditional oral, as in face to face interaction, or written communication, as in letters, to the era of social media where people can communicate wirelessly without having to meet in person change the way people communicate with each other. Social media has become personal necessities for almost every person in order to communicate with their peers, acquaintance, friends, and families. It becomes unseparated part of human life. Thus, social media not only has affected people's personal life, such as interacting with families, friends, and spouses for personal purposes but also their professional life. Mainstream social media platforms provide unlimited amount of information to language learning that change how human acquire information around them. This paper discusses the paradigm shift in education, the positive and negative effects of using social media as a language learning tool, and the conceptual framework in social media based teaching.
\end{abstract}

Keywords: social media; English language teaching; social-media based teaching design 


\section{INTRODUCTION}

We live in the world of rapid growth and changes. In terms of technological advances, we have witnessed the growth of medium of communication from traditional oral, as in face-to-face interaction, or written communication, as in letters, to the era of social media where people can communicate wirelessly without having to meet in person. Not only did these changes occur as unseparated phenomena in human history but they also change the way people communicate with each other. After the telephone was invented, humans have started to leave out communication using letters. Today, the era of social media has also affected the way people interact with each other around the world (Allam \& Elyas, 2016). As we can see nowadays, social media has become a personal necessity for almost every person in order to communicate with their peers, acquaintance, friends, and families. It becomes an unseparated part of human life. Thus, social media not only has affected people's personal life, such as interacting with families, friends, and spouses for personal purposes but also their professional life, such as communicating with the boss, employers, teachers, etc.

\section{Social media as educational tools}

Mainstream social media platforms such as twitter, facebook, instagram, etc. provide abundance information to their users, thus social media, quoting Fewell in Basoz (2016), also 'have ended the limitation of the physical world" by providing unlimited amount of information to language learning that change how human acquire information around them (Fewel in Basoz, 2016 and Allam \& Elyas, 2016). In relation to education, Kessler (2013) added that this understanding gives us opportunities to unlimited amount of meaningful, authentic, and diverse instances of language practices. Language teachers are expected to actively engage and interact with it as valuable source to language learning.

Social media has also caused a paradigm shift in education all over the globe which leads to the emphasis on new parameters in education, as Allam \& Elyas (2016) mentioned in their paper, as collaboration, personalization, as well as user-generated content. Based on this understanding, teachers can utilize social media as one of tools of language learning under those new parameters. 
There are numerous studies that show the advantages of using social media as a tool in language learning but those studies also report several problems posed by the use of social media in education that can hinder the goal of language learning. Therefore, it is important to see social media as two sides of a blade which provides us new insights in language learning but can also poses problems that lurk beneath its surface. Or as Warschauer in Alnujaidi (2016) said that technology, including social media, should not be regarded as "a magic bullet to solve educational problems, but rather as a powerful tool that can have both positive and negative impact, and that must be carefully exploited". It is now then the role of language teachers to design social media based learning that accommodate its positive function at the same time minimize problems that might arise with it in language learning.

\section{DISCUSSION}

\section{Positive Effects of social media in English language learning}

The development of the new media gives numerous benefit to the teaching and learning of English. Below are some advantages of using social media in language education as identified some studies:

1. Help improving students' motivation

The use of social media is reported improve students' motivation in learning. Students perceive learning through social media as enjoying activity. This positive attitudes towards the social media leads to the improvement of students' motivation (Taekke \& Paulsen, 2013; Eren, Sekiguchi \& Kuo in Basoz, 2016; Swain \& Lapkin in Kessler, 2013; Ellison, Steinfield \& Lampe in Kessler, 2013).

2. Facilitate students to collaborate with their peers globally

One of the main potential of social media is to facilitate students to collaborate with each other. As social media also eradicate the geographical borders among language learners in all over the world, it is now possible for students to collaborate with peers across the globe. As a result, it enhance the relationships and interaction among students, between 
students and schools, thus it also improve students' social interaction (Taekke \& Paulsen, 2013; Allam \& Elyas, 2016).

\section{Convenience}

It is also reported that social media is convenient for students to use. It is easy to use, practical and reflect real time situation (Sah, 2015).

4. Suit the nature of today's generation

Most of our students are digital natives. They were born in the era of technology and social media cannot be separated with the life of our students. Thus using social media as language learning tools is suitable with the nature of our students learning style as digital natives (Sah, 2015; Allam \& Elyas, 2016).

5. Allow information and ideas sharing

Social media allow students to share information and ideas to their peers inside or outside classroom globally. It gives students opportunities to take wider response from all over the world which will add to the diversity of the information and feedback they receive (Sah, 2015; Kaplan \& Michael, 2010).

6. Provide new insights in learning.

Social media gives us new insights for learning (Sah, 2015). There is no more excuses of the limitation of teaching materials since it is available around us.

\section{Negative effects of using social media as language learning tool}

However, the development of the new media also pose some difficulties and problems to the students and the teachers:

1. Insufficient facility

Insufficient facility and opportunity for students to participate in nonschool-subject matters. Learning through internet requires certain facilities, such as internet connection and electronic devices. Some schools have difficulties providing these facilities so the language learning cannot be carried out (Taekke \& Paulsen, 2013). 
2. Social media addiction

One of the leading problems in using social media, inside or outside the classroom settings, is addiction. Without proper monitoring and guide from parents or teachers, students can get addicted in using social media. The other cause of the addiction is lack of formative regulations to the new digital media teaching (Taekke \& Paulsen, 2013).

3. Biggest diversion in educational learning

It is also reported that social media is one of the biggest diversion to pedagogical activity. Students tend to use social media outside of educational purposes when engaging in classroom activity (Taekke \& Paulsen, 2013).

4. Students' false assumption of multitasking

Some students might claim that they are capable of using social media for multitasking activity alongside with learning. But in reality, the practice tends to show the other way around (Taekke \& Paulsen, 2013).

5. Teacher's recognition and perception towards the problems

In dealing with this students' problems in using social media inside the classroom setting, teachers might show different reaction. Some teachers might completely prohibit the use of social media inside the classroom activity or completely ignoring the problems at all (Taekke \& Paulsen, 2013).

6. Teachers' reluctance to accept changes. Insist on old methods

Not only students, teachers also have difficulties in dealing with the use of social media in education. One of them is teachers' reluctance to change to accept changes and new approach in teaching (Allam \& Elyas, 2016). This perception usually leads to the second problem below.

7. False assumption of the effect of social media on students

Some teachers have false assumption on the use of social media in educational setting. After they refuse to use social media in teaching, they further think that social media will only give students negative effect on their learning (Allam \& Elyas, 2016). 
8. Create difficulty in maintaining real-life interpersonal relationships

Excessive use of the Internet might hinder students from involving in social activities. As a result, students might not be able to function well in societies and maintain personal relationship in real life situation (Allam \& Elyas, 2016).

9. It can affect student well-being

Too much exposure to social media can also affect students' well-being. Few examples of this is sleeping problems, depression, stress, health conditions, and illnesses, and decreases in self-esteem (Anderson, 2001 in Sah, 2015).

10. It could affect students' grades

If those problems persist, then it would be obvious that they would eventually affect students' grade (Scanlon \&Neumann, 2002 in Sah, 2015). Which is an irony, instead of using social media to improve students' learning, it decreases it.

11. Plagiarism

Another problem found in students is the act of plagiarism. Students can easily take some materials (such as assignments) on the internet without crediting the authors by just simply cutting and pasting it (Scanlon \&Neumann, 2002 in Sah, 2015).

\section{Using social media platforms in foreign language teaching and learning}

Despite of the disadvantages of using social media in education, they are indeed have positive effect towards language learning. Numerous studies has reported the use of various social media platforms in teaching English. There are various social media platforms which can be categorized as Social Networking Sites (e.g. Facebook), blogs/microblogs (e.g. Twitter), collaborative projects (e.g. Wiki), content communities (e.g. YouTube), and virtual social worlds (e.g. Second Life) (Kaplan \& Haenlein, 2010). Those social media platforms provides different impacts to language learning and each of those is specialized in, but not limited to, enhancing different language skills. Some of the examples are mentioned as follows: 
a. Blogs and micro-blogs

Blogs and micro-blogs are one of social media platforms used by students and teachers to learn and teach English. The use of blogs and micro-blogs form an effective means of creating journals without calling for any ICT skills from learners (Wu, 2006 in Basoz, 2016).

b. Twitter

Twitter is used by students to share information and problems, engage in social interaction and communities. Thus, twitter help students promote language learning as well as social cohesion. It is also reported that twitter can be used to improve students' language skills.

\section{c. Facebook}

It is revealed that the EFL learners perceive Facebook as an interactive learning environment promotes learner-learner and learner-instructor interaction and develops a sense of belonging (Razak et. al., 2013 in Basoz). Facebook also give positive impact towards students' grammar and writing skills (Suthiwartnarueput \& Wasanasomsithi, 2012 in Basoz, 2016). It is also reported that Facebook helps students to increase their learning motivation (Kanasin, 2014 in Basoz, 2016).

\section{Content communities}

\section{d. Youtube}

YouTube offers opportunities to access audio-visual materials that may enhance EFL learners' listening comprehension skills. Moreover, it was reported that the use of YouTube encourages student motivation and improves EFL learners' oral and aural skills (Kuo, 2009 in Basoz)

\section{Establishing conceptual framework in social media based teaching}

Based on the understanding of the opportunities and challenges in using social media as teaching tool, teachers must aware of ways to optimize the advantages of social media and to avoid its disadvantages in language learning. Therefore, beside of social media's function to help teacher improve the practice of language teaching and learning, teachers must provide students with with academic 
support and assistance, such as mentoring, tutoring and feedback (Rosen \& Nilson, 2008 in Sah, 2015).

One of the most interesting facts about using social media in education is the variety of ways that it offers to collaborate. Today's technology allows us to create multiple forms of collaborative activities (Kessler, 2013). By optimizing the use of those social media platforms, we can maximize the potential of social media for language learning. By assessing students need and selecting appropriate platforms to serve the needs. Selecting the appropriate social media platforms in another challenge for teachers to do. It is because there are numerous kinds of social media on the internet and not all of them are suitable with our context of learning. Therefore, English teachers today is expected to be able to manage and to sort through the wealth of resources to identify those that are most useful for their own teaching contexts (Kessler, 2013).

In dealing with the problems in using social media in education, Kessler (2013) also argues that there are some basic guidelines for teachers to apply to minimize the problems:

1. Focus on pedagogy. Teachers should remember that social media's function is to assist students' learning. Therefore, before using social media in a classroom setting it is important for language teachers to make sure that the materials they use serve pedagogical function. Teachers can also set up ground rules in the classroom with the students so they can focus on the lesson. It is also possible for teachers to manipulate the technology in such a way that students won't be able to use it outside of educational context.

2. Allow classroom practice to mimic authentic communication.

Even though the teaching is done within the confinement of classroom activity, teachers should relate it to the use of the language in real situation. Teachers can assign students with extra activates to make sure that they practice authentic communication.

3. Don't wait to be an expert. 
Many teachers who are intimidated by technology are inclined to avoid it altogether. Fear of using new methods is a normal reaction. But avoiding it altogether is not a good solution.

4. Ease into new practices.

Always start with something easy. Don't start with something complicated or it will only hinder the learning. Effective integration requires reflection and repeated practice. It takes time and effort to form an effective language learning trough series of practices and reflection, and evaluation.

After all, Kessler (2013) points out that in the attempt to prepare students to engage in English-speaking culture through exposure to the cultural values of the English-speaking world, students should not only be exposed to different opinions but also encouraged to contribute their own values and opinions in the process. This engagement helps to motivate students and support their efforts as language, as well as culture, learners.

It is also important to note that teachers must ensure that their social media based language learning and teaching works hand in hand with the educational paradigm in language education. Such social media must be effectively embedded into education so not only it is relevant with current teaching practice but also based on recent theories of language education (Alshenqeeti, 2018). Furthermore, Norton in Alshenqeeti (2018) added that ensuring the compatibility of social media applications to language learning paradigm is the first step before deciding their benefits in language education.

\section{CONCLUSION}

At the beginning of the discussion, we have witnessed the development of social media technology and its impact towards our aspects of our lives, including education. It changes how we communicate with each other and gain new information from all around us. It also provides us with new way of collaboration with unlimited sources from all over the world. However, not all aspects of social media can be drawn into educational settings. 
In relation to English language teaching and learning, many studies has reported several positive as well as negative in using social media in English language learning. For students, learning through social media improve their language skills, boost their motivation, and help them collaborate with their peers. For teachers, social media helps them to teach students language that suit with their generation. Thus, eliminate boredom in classroom. However, there are also negative effect of using social media in language learning. Some teachers are still reluctant to change their perception towards teaching through social media and technology. They also have fear that social media will give students negative impacts. As for students, misuse of social media is found in language learning, such as plagiarism and using social media beyond educational purposes. It is also found that excessive use of social media can affect students' well beings. Based on the discussion, it is obvious that not all aspect of social media give positive contribution to language learning. That is why it is important to see social media as two side of blades. Teachers should be careful in determining which platforms give more positive contribution to language learning and which do not.

In the end, establishing teaching framework for social media based language teaching becomes the uttermost important task for language teachers. Teachers need to ensure that their social media based teaching practice reflect the educational values. Social media provides almost unlimited amount of possible learning activities so it is also important to make sure that teachers can select and filter the appropriate social media platforms that suit with the context of their learning. Social media play big role in enhancing students' collaboration so teachers should know how to make use the best out of it. Minimizing problems in social media based education is important. Therefore, teachers should make sure that their teaching design reflects this notion. 


\section{REFERENCES}

Allam, Madawi \& Elyas, Tariq (2016) Perceptions of using social media as an ELT tool among EFL teachers in the Saudi context. English Language Teaching: Canadian Center of Science and Education. 9 (7). doi: 10.5539/elt.v9n7p1.

Alnujaidi, Sulaiman (2016) Social network sites as ESL/EFL learning and teaching tools: A Critical Review. International Journal of Applied Linguistics \& English Literature. 6(3). doi:10.7575/aiac.ijalel.v.6n.3p.3

Alshenqeeti, Hamza (2018) Technology in the language classroom: How social media is changing the way EFL is taught. Arab World English Journal (AWEJ) Special Issue on CALL. 4. 55- 68. DOI: https://dx.doi.org/10.24093/awej/call4.5

Basoz, Tutku (2016) Pre-service EFL Teachers' attitudes towards language learning through social media. Procedia - Social and Behavioral Sciences 232 (2016) $430-438$.

Kessler, Greg (2013) Teaching ESL/EFL in a world of social media, mash-ups, and hyper-collaboration. TESOL International Association. 4(4)

Paulsen, Michael \& Tekke, Jesper (2013) Social media and teaching: Education in the new media environment.

Sah, Pramod Kumar (2018) 'Let's tweet to learn English': Using twitter as a language tool in the ESL/EFL classroom. 